\title{
Carolyne Lee
}

\section{$A$ rare brand of intimacy: reconsidering the structure and unique effect of the short story}

\begin{abstract}
In this paper I argue that the short story is a unique fictional form, with its own specific conventions, knowledge of which could usefully inform the teaching of short story writing. There has been very little attempt to explain how a short story means (as opposed to what it means) and it is only by articulating and analyzing specific short story conventions that we can move towards such an explanation. The main 'convention', I argue, concerns the reader's response to the short story: a response that occurs in a context of brief intensity and heightened involvement (due to the aesthetics of brevity), with the story acquired and retained whole' in the reader's memory. This in turn encourages readers to appropriate the fictive world as rendered through one or more represented subjectivities inscribed in the narrative. I have termed this appropriation the 'narratorial presence' of the short story, and I argue that it is the enabling effect of the tale's telling. It occurs in different ways in different stories, predominantly in response to the mix of specific devices used to render different narrative perspectives. Performing analyses of Joyce's 'The dead' and Hemingway's 'The killers', and also briefly examining what I see as a Hemingway-esque Australian short story, 'Tap' by Garry Disher, I demonstrate how each story's structure 'manages' all other aspects of the narrative, facilitating the effect of 'narratorial presence'. A recognition of this effect could, I suggest, renew discussion of, or perhaps even initiate the construction of a new framework for the teaching of short story writing.
\end{abstract}

\section{Introduction}

\footnotetext{
The size of a thing, the quantity of verbal material, is not an indifferent feature; we cannot, however, define the genre of a work if it is isolated from the system ... The study of isolated genres outside the features characteristic of the genre system with which they are related is impossible. (Jurij Tynjanov [1])
}

As a longtime teacher in tertiary writing courses, and as a sometime writer of short stories, I've never felt completely comfortable about the generallyaccepted methodology of the theory and practice of teaching short story writing, as presented in most of the available texts.[2] In general, the explicit aim of the authors of these texts is to isolate and 'teach' what they see as the various facets (for example, characterisation, plot, point of view, descriptive writing, dialogue) of fiction writing as they apply to both the novel and the short story. 
In other words, the writing of fiction is discussed in these texts as if there are not two separate fictional genres. For example, Bernays and Painter, in What If? Writing Exercises for Fiction Writers, [3] manage to conflate the two genres in their first two chapters. In Chapter 1 their first teaching point, derived from Horace, of starting stories in media res, seems to be directed at short story writing, and indeed they utilise as models first lines from 17 short stories; however, in Chapter 2, they state: 'In [Chapter 1], we illustrate how most stories and novels begin in situation, in the middle of things' (Bernays \& Painter 1990: 7; emphasis added). All of the other texts I've examined share in this conflation to a greater or lesser extent.

It cannot be denied that the short story and the novel share similarities; for example 'certain required properties of narrativity - characters, place, events, a "beginning, middle and an end", and coherence among the parts' (Ferguson 1982: 14). But writing or reading a fictional text of, say, 3,000 words is a markedly different experience from writing or reading a fictional text that is 60,000 words long. Much theoretical work on the short story genre has attempted to explore these differences, and to articulate just how the short story and the novel constitute two distinct genres, with quite separate histories, conventions and effects. Of course it can never be argued that each genre possesses facets of a totally different kind from the other, but there are certain expectations and practices in which reside marked and describable differences between the genres.

The writing and reading of short stories, in common with the writing and reading of all other genres, are - as Susan Suleiman articulates - 'communal, context-specific act[s], the result of what Stanley Fish calls shared interpretive strategies and what Jonathan Culler calls reading conventions' (Suleiman 1980: 45). These conventions, or practices established by general usage, include the fact that we recognise separate genres of fiction, that writers construct their texts to conform to (or even to define them against) these generic conventions, and that readers expect certain features from one genre and not from another. It is these 'differing sets of expectations' (Suleiman 1980: 45) in particular, constituting specific generic conventions of the short story, that are the focus of my project. As Culler says, in speaking of generic conventions in general:

One can think of these conventions not simply as implicit knowledge of the reader but also as the implied knowledge of authors ... The activity [of writing and/or reading, say, a short story] is made possible by the existence of the genre, which the author can write against, certainly, whose conventions he may attempt to subvert, but which is none the less the context within which his activity takes place. (Culler 1975: 116)

So while there are similarities between, say, successful short story characterisation and successful novel characterisation, the former genre is nevertheless a distinct and separate one with its own unique (and far longer) history, a history that must have inevitably forged specific practices in approaching a text called a short story. It is in this sense that I consider the short story to possess its own quite specific conventions. Yet, except in rather brief ways,[4] nobody seems to have articulated the conventions of the short story, much less articulated them exhaustively and satisfactorily.

The absence of the articulation of short story conventions in the corpus of short story theory is mirrored in the teaching texts, except for the occasional brief discussion of how the short story differs from the novel. One of the most helpful of these discussions is by Janet Burroway. Like the other texts, her book deals with individual facets as they relate to fiction in general, but also 
devotes a short section quite early in the book to a discussion of the differences between the short story and the novel. Her discussion raises several points which seem at one stage to be moving in the direction of a delineation of some short story conventions: brevity, a single emotional impact and a single understanding, economy of style. She acknowledges that all of these (except brevity) are also praiseworthy in a novel, but that these are not the only possibilities for the novel, whereas for the short story they must be: and these delimited possibilities directly affect the relationship between story and plot in the short story. In the same section, however, she seems to undercut her own movement towards some acknowledgment of specific generic conventions by asserting the sentiment that has enraged many short story theorists: despite one form not being superior to the other, she says, 'it is a good idea to learn to write short stories before you attempt the scope of the novel, just as it is good to learn ... to draw an apple before you paint a god' (Burroway 1992: 52). And her view takes another twist in the next sentence: 'Nevertheless, the form of the novel is an expanded story form' (52-53). The rest of the book comprises various facets of narrative craft, such as 'Showing and Telling', 'Characterization', 'Atmosphere', 'Point of View', 'Theme', and even 'Revision', all of which are to be considered, it is explicitly stated, as equally relevant to the two genres.

This presentation of short story facets in isolation from short story conventions is rather like teaching vocabulary in categories such as nouns and verbs in, say, a language such as German, without also teaching the student the grammatical conventions of that particular language - conventions that determine the specific word order in sentences, and the ending of nouns according to the grammatical case of the sentence. Without competence in these conventions the language can never be properly mastered: learners will hardly be able to understand fluent German when they hear it; even if they themselves can produce sounds resembling German words and perhaps can even be understood at a very basic level, what will be produced will not be successful linguistic performance in that language, because 'performance is impossible without competence' (Chomsky in Pratt \& Traugott 1980: 15). By analogy, then, this is what I believe tends to happen in the production of 'stories' by beginning short story writers as a result of the generally accepted method of short story writing pedagogy.

There has been, I argue, very little attempt to explain how a text that is written as a short story means, as opposed to what it means (the function of most literary interpretation). The lack of a coherent articulation of conventions of the short story is therefore a major gap in the pedagogical literature, and for its causes we need to look at the theoretical literature, a body of work that ranges widely in its content: from delineating and describing certain criterial features, and diagramming all possible plot types, to arguing that the short story has its own unique epistemology. And, like a palimpsest, faintly discernible beneath all these views are those of Edgar Allan Poe, written in 1842: the short story must be able to be read at a single sitting; it must above all produce a single effect (Poe 1842/1964: 978). That seems to be about the only firm ground, but it hardly constitutes a theory of the conventions of the short story, let alone a basis for the teaching of it.

Clearly, writers of short stories have mastered (consciously or unconsciously) the conventions of the short story genre, and must therefore understand how these conventions differ from those of other genres; otherwise, how could they make the decisions that a particular text be a short story rather than a narrative essay, for example, or a long prose poem, or even a novel that was never continued beyond its first chapter? One thing is clear: a short story, in the twentieth and twenty-first centuries at least, is a piece of prose fiction with a 
word length within the range of 1,000 to approximately 12,000 words so that it can be, and usually is, read at one sitting. The only characteristic, then, on which all critics are agreed, is brevity. This characteristic of brevity is the marker by which prose fiction can be regarded as a short story, as opposed to a novel or a novella. For the moment, we will regard the upper limit of the short story as 12,000 words, although this is far longer than the norm for late twentieth- and twenty-first century short stories.[5]

If it is brevity, then, that sets the short story apart from the longer fictional genres of novella and novel, what are the corollaries of this? It seems we cannot proceed until we have dealt with the inevitable comparison between the short story and the novel, although short story theorists argue that the short story should not be automatically defined against the 'fictional norm' that they claim the novel has become. Even so, some prefatory remarks need to be made about how a short reading act differs from a lengthy one for the reader. Perhaps it is appropriate to evoke analogies such as a comparison of a tot of brandy with a tall glass of brandy and dry? That the two drinks, despite sharing the same main ingredient, have different tastes as well as different effects on the drinker is without question. But perhaps a better analogy would be to compare a 'romantic fling' with a ten-year marriage: in the former the interaction would be unquestionably more intense, uninterrupted by other facets of life, and therefore more focused; yet no matter how enjoyable, one would not wish for that calibre of interaction to be sustained over a much longer period. Any short story reader, I believe, could identify with this view.

Such analogies aside, it is obvious that a single, whole aesthetic experience, completed by a reader in a time span of somewhere between, say, five and 50 minutes, cannot avoid being qualitatively and quantitatively different from one which takes a reader from three to six hours. Given the range of the human attention span, it is quite possible to attend to nothing but the reading experience while reading a short story. Even if one can read a novel at a single sitting, it cannot be done in any time frame that could be termed 'brief' when talking about a reading experience, and in most cases the experience would be interrupted a number of times by meals, trips to the bathroom and so on. Except in rare circumstances, reading a novel does not provide one with a single, whole, uninterrupted aesthetic experience that is accomplished in a brief period of time. Neither will the reading of a short text that is a piece of fiction but was not constructed and presented as a short story (a chapter, or summary, for example, or an unsuccessful short story - one that does not 'work' as a short story); that reading experience may indeed be accomplished in as brief a time as the short story, but it will not provide a single, whole fictional aesthetic experience; the feeling the reader will be left with is that the text is an extract, or a summary of something longer. Only a short story will provide a feeling of wholeness and completeness in a brief time span.

Because of its brevity, then, the short story can be read in 'one sitting' without the intervention of ordinary life; and this single focus usually engenders a heightened aesthetic arousal. Suzanne Hunter Brown, in her important paper on the aesthetics of brevity, cites the findings of psycholinguists to support her argument that the length of a text can affect readers' 'perceptual tendencies' (Brown 1982: 28). Valerie Shaw articulates a similar view when she states that fictional brevity can 'intensify the reader's gaze and ... produce a rare brand of intimacy between reader and story' (Shaw 1983: 61). She does not, however, develop this notion of the 'rare brand of intimacy'. In addition to the intensification, though, there is the pragmatic consideration of a brief text being able to remain entire in readers' memories, to be conducive to being read, perceived, remembered as a whole: the beginning is usually still clear in readers' minds as they finish reading the concluding sentences. 
Discussing fiction in general, Paul Ricoeur states that the 'end point' of a story 'furnishes the point of view from which the story can be perceived as forming a whole' (Ricoeur 1984: 67). It is no accident that short stories frequently end similarly to how they begin, in a thematic, temporal or spatial sense. A character is often described as coming 'full circle' in a certain situation, or the narrative returns to the opening scene, or else there is an explicit return to a theme first articulated at the start. Discussing his own practice of teaching short story writing, Kevin Brophy says, 'I keep telling students it is the ending of a story that throws a decisive shade of colour back over everything that has been written' (Brophy 2003: 226).[6]

This effect is rarely the case with novels, [7] although with both genres of fiction, readers may strive to create a conceptual whole from their experiences. Clearly, with a short story, its very brevity dictates that at the conclusion of the reading experience, this conceptual whole is much more clearly defined for the reader because the text was perceived and read as a whole, complete and succinct experience. This is not to suggest, however, that in the short story everything is spelt out for the reader in a seamless flow of intricately detailed narrative. This is actually much more the case in a novel, simply because in that genre there is more room. In contrast, the short story is frequently described as elliptical or lacunal in nature; the details readers 'remember' may even be details they have constructed in their own imagination to fill the gaps in the text. As Brophy states: 'many modern short stories, particularly since Hemingway ... [are] characterized by narrative ellipses. ... It is as if readers and writers have become familiar enough with such stories ... not to have to be told everything' (Brophy 2003: 225). This would seem to be echoed by Burroway, who could be speaking for all short story writers, or teachers of short story writing, when she says that when writing a short story one must 'reject more, and ... must select more vigorously' (Burroway 1992: 52).

Chamberlain believes that the impetus of readers to construct a conceptual whole from each reading experience is a dimension of one's scope as a reader, and surely this scope is stretched - intensifying the reading experience - when reading a text that is elliptical, which tells the story as much by what it leaves out as by what it actually narrates. And if the greatest ellipsis or 'gap in any text is that found between its end and its beginning' (Chamberlain 1990: 135), it is obvious that in a short story this end comes much more quickly after the beginning, and while the beginning is still clearly in the reader's mind. The narrative perspective usually remains constant, too, in the short story, reinforcing the concise and sharply-focused quality of the brief reading experience.

These psycholinguistic phenomena, then - the acquisition and retention in the reader's memory of the whole story in all its detail, and the heightened 'intimacy' or involvement between reader and story - arise from the brevity of the text, and are phenomena that experienced writers (consciously or unconsciously) take into account when constructing the text, and that readers (again, consciously or unconsciously) anticipate and facilitate when they come to read a short story. But these phenomena do not, of themselves, constitute conventions. They are the background, or perhaps the raw material from which the actual conventions can be constructed. I am using the term convention in the sense of established practices, but also, given Culler's argument that generic conventions are 'sets of instructions' or 'contexts', in the sense of all of those elements of the story (constructed by the writer) that furnish competent readers with sufficient information to engage in that certain practice. Now, if that practice takes place in a context of brief intensity and heightened involvement, clearly it will be a different practice from one that takes place over a period 
sufficiently long that intensity varies and in which consistent heightened involvement is not possible. Moreover, given that the reading experience does not end at the final word that is read, the practice that can be engaged in and retained whole and in detail is clearly going to be different in quality from the practice that cannot.

This difference, I believe, lies in the level of readers' appropriation; that is, the extent to which they take on and make their own the represented

consciousnesses and/or the fictive world. In a short story, due to the effects of brevity, it will be an extremely strong and thorough appropriation, but only if readers are 'short story competent' readers; that is, if they have a certain awareness of the aesthetics of brevity, and are attuned to consuming the story as a conceptual whole complete with every detail. If these conditions are met, the conventions or 'set of instructions' will give rise to their main effect and enabling condition: an effect that doubles back on itself to read everything in the story through its lens, drawing the reader in with it -- to the fictive world, which both is and is not the real world - through this narrow and highlyfocused aperture.

I have termed this effect the narratorial presence of the short story. The many facets of the short story - such as characterisation, plot, voice, metaphor and metonymy, point of view and pronominal choice - are mediated only by way of the narratorial presence which is created in the interaction between the type of narrative perspective through which the author has rendered a particular text, and readers' perceptions of this narrative perspective; these dimensions then being transformed into the virtual relationship between reader and the fictive world. I need to make a distinction here between my term, narratorial presence, and what I regard as its main contributing factor: narrative perspective. As Chamberlain points out, narrative perspective has long been regarded by narrative theorists as the 'essence of narrative art' (Chamberlain 1990: 3). Although seemingly and most inexplicably overlooked by short story theorists, it is my figuration for what I believe is the most crucial element of all fiction. It is perhaps somewhat analogous to the combination of positioning of the aperture of the camera lens used to make a film and the film's focal perception/ character: this combined perspective determines not only what we see and what we do not see, but how we see it -- which aspect, at which angle, in which light; all of which go to make up the specific aesthetic effects of any fictional text. The fictional text, then, can only be, and is always, presented from a certain narrative perspective. This perspective, as Chamberlain states, 'functions at all moments of the narrative experience' (1990: 4), and although constructed initially by the writer, needs to be taken up by the reader (in the same way a film needs a viewer) in order to be given 'life'. This of course occurs in all genres of fiction. But this 'life' flowers into a peculiarly intense, because brief, experience in the case of the short story, thus forming the narratorial presence.

The narratorial presence is my own term for what I believe is the short story's unique effect, formed by the intense encounter between the text - and specifically the text's narrative perspective - and the reader. With any fiction, readers use the details supplied in order to do their share of the work to produce the aesthetic object; in this case to create images in their heads - a fictive world complete with temporal and spatial form, and to enter that world. But when the text is a short story, readers, aware in advance of the conventions - knowing how the brief time frame involved will generate a heightened involvement, perceiving all details much more vividly, and reading the concise, lacunal prose through the frame of these expectations - allow themselves to be drawn into the fictive world in a more total and abandoned way than they would when reading a longer narrative. I am arguing for teachers of short story writing to facilitate 
in their students an awareness of this phenomenon, initially by studying published short stories.

This difference between the reading experiences of short and long prose has been inadvertently signposted by Wolfgang Iser. He has stated that the first problem when attempting 'to describe the intersubjective structure of the process through which a text is transferred and translated ... [is that the] whole text can never be perceived at any one time ... [differing] from given objects which can generally be viewed or at least conceived as a whole' (Iser 1978: 108-9). By the 'whole text' he was referring, of course, as are almost all narrative theorists, to the novel. The perceptual process of reading the novel is encapsulated by Iser in his term the 'wandering viewpoint', a term which describes how the reader constantly switches between textual viewpoints. This switching occurs as a result of the interplay between the text and individual readers' meaning-making, an activity that causes readers to form expectations as they read; these expectations ('protentions') are constantly being modified as new text transforms the already-read text ('retentions') in the reader's mind.

In contrast, when reading a short story, readers' memories of what they have read so far (or retentions) are much more coherent than when reading a longer text, because when reading a text that can be read at a single sitting there is a great deal less in the way of 'past horizon' or background into which the story can fade. In a short story the dialectic of protention and retention which constitutes the reading moment is condensed, and therefore one would reasonably expect the experience to be a very intensified one for readers.[8] Unfortunately Iser does not even consider that this might be what happens when the text can be viewed or conceived as a whole. In my view, the heightened intensity of short story reading encourages readers not so much to 'switch' (as would be the case, according to Iser's concept of the 'wandering viewpoint', when reading a novel) as to achieve a sort of configurative synthesis: in this way they are able to 'become' the narrator, the main character, the narratee, the implied reader, in the type of supersubjective and intersubjective experience I described earlier.

As an illustration of this we only have to look at 'The Dead' by James Joyce (1994: 21-59): at times we emotionally identify with Gabriel Conroy, and at others we see him from a distance, described in the narrator's words. But in such situations we are not conscious of 'switching' so much as of having double or triple vision. This enhanced vision is one of the functions of the heightened effect of brevity. In a short story (even a long one such as 'The Dead') we know that everything matters - every sentence and word must justify its inclusion and we cannot turn away from one perspective to concentrate on another. We must find a way of synthesizing all perspectives in order to give life to the intense emotional experience that is the raison d'être of the short story.

This configurative synthesis, then, is what enables short story competent readers to construct a super-subjective relationship from the represented subjectivities in the story, and every aspect of these subjectivities is governed by the narrative perspective in which the story is rendered. So the supersubjectivity will differ in nature from story to story, depending on the effects produced by the range of techniques employed to render the many different facets of a particular narrative perspective. Despite the myriad different effects possible, constituting narratorial presence, or way of being 'in' the story, the phenomenon of narratorial presence itself can be thought of as occupying one or a blend of two broad categories. These categories are not mutually exclusive, and in many short stories they occur in mixed form. Both involve intense imaginative participation in the reading of a short story. 
The first effect can be likened to a 'daydream' type of presence in the story, in which the reader identifies with one or more of the represented subjectivities. In interacting with perspectival features that engender this type of presence, we tend to suspend disbelief and do not question the logic of the represented world, but merely follow it, through our melded consciousness with the object of our identification. As Hubert Zapf describes it: the reader is 'drawn into the imaginative world of the text. His psyche is brought to experience the fictitious world under the simulated conditions of "real life"' (Zapf 1990: 101).

The second effect is brought about by perspectives that distance readers from the narrative, and from the characters. With no melding of consciousnesses, we have little insight and therefore are less able to accept the story's internal logic. But because we are operating under the assumption that a unified, whole, aesthetic experience is the generic convention, we have to harness our intense imaginative participation to the self-conscious construction of the fictive world.

Stories with narrative perspectives constructed in ways that encourage solely this second type of response (as opposed to a hybrid) for the entire story do not constitute more than a small percentage of stories published in mainstream sources. Examples of a 'distancing' narratorial presence can be found in some of Hemingway's most famous stories, such as 'The Killers' (Hemingway 1955: 279). Discussing other Hemingway stories, Zapf calls this self-conscious type of presence in the story a 'reflective consciousness', and elaborates by explaining the following:

philosophy distinguishes [reflective consciousness] from the naïve consciousness and its 'natural attitude' toward reality. In the act of reflection the subjective consciousness 'turns back' upon itself, distancing itself from immediate experience and questioning all apparent certainties and determinacies of the everyday world ... the reflecting consciousness becomes aware of its own constitutive role in the structuring and interpretation of the 'objective' world ... [Thus the reader] is conceived as an all-pervading critical consciousness which explicates itself in progressive acts of (self-) reflection. (Zapf 1990: 101)

It can be seen from this that the two types of effect are complementary rather than contradictory, and perhaps could be seen as occupying each end of a continuum describing broad types of narratorial presence. To illustrate the differences between the two types I will now turn to a detailed discussion of 'The Killers' and 'The Dead', arguably among the best known in English short fiction.

Both of these stories would be referred to, according to the blunt frameworks of the teaching texts, as stories told in 'third person' narration; however, they could not be more dissimilar in terms of the type of narratorial presence readers can construct from the respective reading experiences: that of 'The Killers' is towards the 'reflective consciousness' end of the continuum, while that of 'The Dead' is towards the 'daydream' end, although incorporating some reflective elements. 'The Killers' is a prime example of a story that presents, in Zapf's words, only 'reduced, incomplete outlines and "component parts" of an imaginary world' (Zapf 1990: 98) that the readers must take and flesh out before being able to construct the aesthetic object that is the fictional setting. These 'reduced, incomplete outlines' occur because the story is told almost entirely in direct speech.

The plot of this very wellknown story is simple, if elliptical. First, two men enter Henry's lunchroom. Their names are Al and Max. They converse angrily 
with George the waiter because he cannot give them items from the dinner menu for another hour. A young man named Nick Adams, an acquaintance of George, is at the other end of the counter. Al and Max then order Nick to go around the other side of the counter. Al ties up Nick, and also Sam the cook, out in the kitchen, and puts gags in their mouths, while Max stays out the front with George. Max tells George they have come to kill 'a big Swede, named Ole Andreson' (Hemingway 1955: 283) who usually comes into the restaurant for dinner at six. The men seem to be carrying sawn-off shotguns. After about an hour of waiting for Andreson to come in, the two men give up and leave. George unties Nick and the cook, explains whom the men were after, and suggests that Nick goes to where Andreson lives to warn him. When Nick arrives there he finds the man, an ex-heavyweight prizefighter, lying fully dressed on his bed. When Andreson is told about the two men who want to kill him, he shows no surprise and refuses Nick's offer to go to the police, seeming resigned to his fate. Back in the eating-house, Nick, clearly distressed about the situation, relates Andreson's reaction to George, and finally vows to 'get out of this town' (Hemingway 1955: 289).

Apart from the way certain lines of dialogue suggest a particular character's feelings and reactions, 'The Killers' offers few glimpses into the minds of its characters. The authorial narration is external, in the sense that it does not give access to anyone's mind, and we are presented with only what can be observed or heard. Because of this, right from the beginning there is a complete absence of any sense of a unifying subjectivity, and we may even feel there is no narrator, only a sort of focus, impersonal as a ghostly movie camera, operated by no human yet moving around by itself. In a novel, we would be given the salient details of at least the main character, if not immediately, then before too long, because such a lengthy 'objective narration' as this would be unsustainable.

In their analysis of this story, Cleanth Brooks and Robert Penn Warren long ago articulated what happens with some readers early in the story: 'a certain kind of reader, upon first acquaintance with the story, is inclined to feel that the story is exhausted in the first scene, and in fact that the first scene itself does not come to focus, does not have a "point"' (Brooks \& Penn Warren 1975: 188). This could well be a fairly typical reaction of readers not familiar with the full range of responses (or variations in narratorial presence) that the conventions of short story reading require. In contrast, more sophisticated readers will realize by the end of the first scene, if not earlier, that in order to proceed with this story, in order to be 'present' in this story's world, we are compelled to engage in the intense reflection needed in order to figure the 'point' and 'meaning' of the story. Without this reflection, we cannot sufficiently believe in this story to create its fictive world. And so by about the end of the second page, the reader has a choice: either that the story has no 'point' and is not worth reading, or that we can try to construct what we think is taking place by an intense and reflective imaginative participation; and in this way we can consciously construct a narrative world that can accommodate the distanced perspective with which are rendered the narrator, and the characters, especially the main character of Nick.

It follows, then, that our first entry-point into the story, as it were, or the beginning of our construction of our narratorial presence, is one of an extremely slight, almost unconscious intersubjectivity with the effaced narrator. But in addition we feel some empathy with Nick and/or George (even though we realize we have no idea what they are thinking) because we know they are facing a situation that is more awful than they at first can know. And so the initial stage of our intense reflective work is to imagine what the characters must be feeling, while first being addressed so irascibly, and then being ordered around by the armed men. Throughout this scene, they/we feel completely 
confused and dislocated because they/we can find no reason for what is going on, and indeed must try to supply the missing context them/ourselves. In this way, we mirror the two characters' thought processes, an activity that causes a certain amount of intersubjectivity, albeit one that does not allow the intersubjective closeness we are used to experiencing with a character in a 'daydream' type of narratorial presence.

In addition to what Iser has termed the 'wandering viewpoint' (Iser 1978: 114) subconsciously aligning us with the effaced narrator one moment, causing us to empathise with Nick and George at another - we also experience a rising tension. This tension does not come to us presented through the consciousness of any of the characters, but arises in our own minds as we wonder who is going to be the victim of these 'killers'. At first we might predict it will be Nick or George, but this protention is quickly modified when the killers state explicitly the name of the man they intend to kill. At this, we are brought to reflect upon and imaginatively construct this highly charged scene; and in this way we build up the context and connections between the component parts, to construct the fictive world from the raw materials in the text, and to construct our own presence within it.

This presence is not so much experiential, as in a daydream, but more as if we are imagining ourselves watching a play. Thus Iser's notion of the reader's 'moving viewpoint' being the 'conditions that necessitate consistency-building on the part of the reader' (Iser 1978: 16) works somewhat differently in the heightened intensity of the short story reading experience: the 'wandering viewpoints' (made up of different and constantly-changing retentions and protentions) are telescoped, with the fictive world continuously present to us for a period of consistent intensity. Moreover, in a story such as 'The Killers', the unusually high percentage of direct speech, coupled with the absence of characters' thoughts, causes what Iser terms 'blanks' or 'vacancies' (Iser 1978: 198) in our apprehension of the story. Yet it is these very blanks or vacancies that, paradoxically, function as 'guiding devices for building up the aesthetic object' (Iser 1978: 198), an activity that is foregrounded because of the intense reflective consciousness we need to maintain in order to construct the fictive world of this story.

Modern Australian short stories are often characterized by Hemingway-esque narrative ellipses, bearing out Brophy's assertion, quoted earlier, that due to the influence of Hemginway's stories, readers and writers since then have adopted the convention of filling in the gaps in the short story. One such example is the short story 'Tap' by Garry Disher, from his collection The difference to me (Disher 1988), about a young couple's relationship in a period of difficulty, narrated similarly to 'The Killers' in the 'third person', with the young woman occupying the perspectival equivalent of the 'Nick' character. As with 'The Killers', the main narrative ellipses in 'Tap' are principally caused by the absence of characters' thoughts, offset as this convention often is by a high percentage of direct speech. In contrast to the storyline of 'The Killers', though, which is structured to take place over a period of around two hours, the events narrated in 'Tap' take place over a period of around six months, with each break in action or time signified by numbered 'episodes', each episode comprising one to several paragraphs, the shortest being six lines long. This structure has the effect of creating even more ellipses, both temporal and conceptual; blanks that nonetheless guide the reader to build up the aesthetic object by imagining the main character's thoughts and feelings, and life in general during this period, especially her thoughts, none of which we are ever given, despite some quite momentous events forming the plot (equally elliptically, she is known only as 'she'). As with 'The Killers', intense reflection is encouraged on the part of the reader, so that we share the main character's abrupt sense of shock and 
guilt at the end of the story, an ending that will work in synergy with the reader's reflective consciousness, to circle back to the beginning - filling in the ellipses - to form a unified whole.

A reflective consciousness is needed also at the start of 'The Dead',[9] mainly because of what appears to be a type of authorial narration, instead of a narration that places us firmly in a particular character's consciousness, a device that would signal the start of a 'daydream' type of narratorial presence. Possibly one of the most anthologised of English short stories, Joyce's 'The Dead', depicts an evening in the life of Gabriel Conroy. Gabriel and his wife Gretta attend the annual dance party held on the Feast of Epiphany at the Dublin home of Gabriel's aunts, at which Gabriel always makes the speech. Gabriel, a university lecturer and literary critic, experiences a couple of unsettling contretemps during the evening, first with the maid, and then with a nationalist friend. After the party, he and his wife spend the night in a local hotel, where - after another contretemps, this time with Gretta - he falls asleep beside her, contemplating his own mortality.

Although, as I asserted above, 'The Dead' starts with authorial narration, before long the narrator begins to share a good deal of the narration with the main character and protagonist Gabriel. Gabriel can be termed a 'figural' character, a term for the character through whose consciousness the author presents the events of the inner world, and/or the reflection of events of the outer world. But even when it is the narrator telling the story in 'The Dead', this rendering then alternates with a method that glides quickly into Gabriel's consciousness, almost 'zooming in', as it were. It is these increasingly long passages, told from Gabriel's perspective, that strengthen our intersubjectivity with the character and facilitate the construction of a narratorial presence that seems towards the 'daydream' end of the continuum.

There is, however, significant oscillation between the narration from Gabriel's perspective and the authorial narration. The authorial narration, which partakes of no character's consciousness, gives descriptions of the scene and renders direct dialogue. The first instance of authorial narration (apart from the opening passage of the story) is where Aunt Kate asks Gabriel to 'slip down ... like a good fellow and see if [drunken Freddy's] all right ...' (Joyce 1994: 26) Gabriel goes down the stairs, but the narrative is still focused on the scene at the top of the stairs, where Aunt Kate is talking to Gretta. It is another page or so before the narration resumes Gabriel's perspective again, by rendering his private thoughts. This direct access to Gabriel causes us to experience aesthetically his feelings, in particular his agitation, because in such passages our narratorial presence (our specific way of being in this particular story) impels us to sympathetically identify with him, to experience 'being in his shoes', as in a daydream.

Despite the daydream quality of this narratorial presence, we are not always in Gabriel's shoes. When the authorial narration breaks in, as it does from time to time, our connection with Gabriel is disrupted, and we see Gabriel from a slight distance. The first and possibly the clearest example of this occurs on the third page of the story when the authorial narrator describes Gabriel's physical appearance, a description that appears to have been perceived from a couple of metres away:

He was a stout tallish young man. The high colour of his cheeks pushed upward even to his forehead where it scattered itself in a few formless patches of pale read; and on his hairless face there scintillated restlessly the polished lenses and the bright gilt rims of the glasses which screen his delicate and 
restless eyes. His glossy black hair was parted in the middle and brushed in a long curve behind his ears where it curled beneath the groove left by his hat. (Joyce 1994: 23)

From here onwards, the narrative voice alternates between Gabriel's 'private language', and the narrator's 'public language' and also at times a voice in which, according to John Paul Riquelme, the 'narrator's perspective and the character's have been subtly mingled and merged' (Riquelme 1994: 222). But it is our access to Gabriel's private thoughts in particular that strengthens our intersubjectivity with this character and facilitates the construction of the narratorial presence that encourages us to experience the story at least in part from Gabriel's perspective, as if we are playing his role. This 'daydream' effect could not occur with 'The Killers' because of the lack of access to any character's private thoughts. Because of this lack of access, we had to work much harder to construct and then place ourselves in the fictive world, creating a narratorial presence of the intensely reflective kind.

My two brief analyses of these wellknown stories should serve to show that the recognition of the effect of narratorial presence is crucial in approaching a short story. And this recognition, in turn, requires that we renew discussion of, or perhaps even begin to construct a complete new framework for, the teaching of short story reading and writing. The basis of this framework might well be an examination of the ways in which we read different types of stories, an examination that could feature analyses of stories grouped broadly in terms of the techniques used to render each type of narrative perspective; this grouping could function as a heuristic device to encourage the viewing of short stories first in terms of their narrative perspective and the potential effects engendered by the reader. For it is these effects that go on to enable the text and reader together to forge what I see as the main convention of the short story, its metaeffect, born of brevity - the narratorial presence - a phenomenon that 'manages' the entire aesthetic experience of the short story, from the writing to the reading and analyzing.

Such an exploration would necessarily examine the devices used to provide readers with the appropriate 'instructions' for generating the specific effects needed to construct each particular type of narrative perspective. The almost unlimited variety of effects produced from different combinations of features of narrative perspectives would then become explicit, engendering a new look at what is one of the earliest and certainly the longest-surviving narrative forms. The longevity of this genre is surely due in no small way to its participatory impetus. Responding to specific instructions, readers are transported from their everyday world into another. In this other world, or rather, in our own adventures within it, we are not passive recipients. With the text, we co-create the narrated experience in various ways depending on the different devices comprising the story; and it is in this way that we end up telling, hearing, and most of all experience, 'our very own adventure'.[10]

\section{Notes}

1. Quoted in Suzanne Hunter Brown 1982, '"Tess" and Tess: an experiment in genre,' Modern Fiction Studies 28.1: 43; no details of the source of this quote are provided, and despite extensive searching none have been found. return to text

2. See for example Janet Burroway 1992, Writing fiction: a guide to narrative craft; Anne Bernays and Pamela Painter 1991, What if? writing exercises for fiction writers; Carmel Bird 1988, Dear writer; Garry Disher 1989, Writing fiction: an introduction to the craft; Kate Grenville 1990, The writing book: a workbook for fiction writers. return to text 
3. The authors state that the exercises in this work 'represent the most successful examples of more than a hundred exercises used ... in ... teaching ... Each exercise isolates a particular element of fiction, such as dialogue, characterization, subtext, and so on' (Bernays and Painter 1991 xviii). return to text

4. One useful and important exception is Suzanne Hunter Brown's 1982 paper. In this, Brown shows how a reader brings different expectations and therefore a different intensity and focus to a work termed a 'short story'. return to text

5. Of course, word lengths of short stories vary greatly from era to era and, in any case, 'short' can never be anything but a relational term. return to text

6. Brophy's comments comprise some of the few precise, relatively recent technical comments on teaching the short story, by an Australian writing teacher, that I was able to find. Academic attention to the short story, especially with a technical focus, has always been relatively sparse; nevertheless, I would refer interested readers to the following: Angelo Righetti's edited Theory and practice of the short story: Australia, New Zealand, the South Pacific (2006) which includes interviews with short story writers; and Steven Earnshaw's edited The handbook of creative writing (2007) which, while not including a specific section on the short story, does include more general chapters on writing, by Australian writers/writing teachers Paul Dawson and Tom Shapcott. return to text

7. One notable exception is of course The golden notebook by Doris Lessing. return to text

8. Indeed, 'condensation' and 'intensity' are terms on hears frequently in the theoretical literature on the short story, although these terms are used rather nebulously in reference to the 'language' or 'structure' of the story, rather than to the phenomenology of the act of reading, or - to put it more simply - to the description of the nature of readers' responses to the story. See for example George E Haggerty, Gothic fiction/gothic form, 1989. return to text

9. Although several critics regard 'The Dead' as a novella, I consider it a short story for three reasons: first, it sits comfortably within the aesthetic parameters of the short story that I outlined earlier; second, it is treated as a short story by the majority of critics; and, third, it has been included in numerous anthologies of short stories. return to text

10. Henry James's original phrase, describing this effect on the reader, was 'our own very adventure'; but equally, and less archaically, we might describe it, as I have here, as 'our very own adventure' (James 1962 [1907]: 70). return to text

\section{List of works cited}

Bernays, A and P Painter 1990 What if? writing exercises for fiction writers, New York: Harper Collins return to text

Bird, C 1988 Dear writer, Melbourne, Vic: McPhee Gribble/Penguin return to text

Brooks, C and R P Warren 1975 'The killers' in JJ Benson (ed), The short stories of Ernest Hemingway: critical essays, Durham North Carolina: Duke University Press return to text

Brophy, K 2003 Explorations in creative writing, Carlton Vic: Melbourne University Press return to text

Brown, S H 1982 '"Tess" and Tess: an experiment in genre', Modern fiction studies 28.1: 25-44 return to text

Burroway, J 1992 Writing fiction: a guide to narrative craft, New York: Harper Collins return to text

Chamberlain, DF 1990 Narrative perspective in fiction: a phenomenological mediation of reader, text and world, Toronto: University of Toronto Press return to text

Culler, J 1975 Structuralist poetics: structuralism, linguistics and the study of literature, London: Routledge and Kegan Paul return to text 
Disher, G 1988 The difference to me, North Ryde, Sydney: Angus \& Robertson return to text

Disher, G 19891989 Writing fiction: an introduction to the craft (2nd rev ed), Ringwood: Penguin return to text

Earnshaw, S (ed) 2007 The handbook of creative writing, Edinburgh: Edinburgh University Press return to text

Ferguson SC 1982 'Defining the short story: impressionism and form', Modern fiction studies 28.1: 13 return to text

Grenville K 1990 The writing book: a workbook for fiction writers, Sydney: Allen \& Unwin return to text

Haggerty G E 1989 Gothic fiction/gothic form, University Park \& London: Pennsylvania State University return to text

Hemingway, E 1955 'The killers', in Ernest Hemingway, The short stories, New York: Scribner's Sons, 279-89 return to text

Iser, W 1978 The act of reading: a theory of aesthetic response, London and Henley: Routledge and Kegan Paul return to text

James, H 1962 [1907] The art of the novel, London and New York: Charles Scribner's Sons return to text

Joyce, J 1994 'The dead', in DR Schwartz (ed), The dead/James Joyce, Boston and New York: St Martin's Press, 21-59 return to text

Poe, EA 1964 [1842] 'The philosophy of composition' in AH Quinn and EH O'Neill (eds), The complete poems and stories of Edgar Allan Poe, vol 2, New York: Alfred A Knopf, 978-87 return to text

Pratt, ML and EC Traugott 1980 Linguistics for students of literature, Orlando: HB return to text

Ricoeur, P 1984 Time and narrative (trans K McLaughlin and D Pellauer), vol 1, Chicago:

University of Chicago Press return to text

Righetti, A (ed) 2006 Theory and practice of the short story: Australia, New Zealand, the South Pacific, Verona, Italy: Universita de Verona return to text

Riquelme, J P 1994 'For whom the snow taps: style and repetition in "The Dead"', in DR Schwartz (ed), The dead/James Joyce, Boston and New York: St Martin's Press, 222-24 return to text

Shaw, V 1983 The short story: a critical introduction, London: Longman return to text

Suleiman, S R and I Crosman 1980 The readers in the text: essays on audience and interpretation, Princeton: Princeton University Press return to text

Zapf, H 1990 'Reflection vs. daydream: two types of the implied reader in Hemingway's fiction', in JJ Benson (ed.), New critical approaches to the short stories of Ernest Hemingway, Durham North Carolina: Duke University Press, 96-111 return to text

Carolyne Lee has written for newspapers, books, e-zines, educational curricula, and scholarly journals. She has been teaching writing for over twenty years, and is a lecturer in the School of Culture and Communication at the University of Melbourne. Her latest book is Word Bytes: writing in the information society (Melbourne University Press, 2009). 
Keywords: short story; conventions; narrative structure; Joyce; Hemingway; Disher

\section{TEXT}

Vol 13 No 2 October 2009

http://www.textjournal.com.au

Editors: Nigel Krauth \& Jen Webb

Text@griffith.edu.au 